\title{
Experimental investigation of proppant clustering in intersected fractures
}

\author{
Wenpei Ma ${ }^{1} \cdot$. Ingrid Tomac ${ }^{1}$
}

Received: 7 December 2020 / Accepted: 25 February 2021 / Published online: 15 March 2021

(c) The Author(s) 2021

\begin{abstract}
This paper investigates the dynamics of proppant agglomerations during flow and transport within fractures intersected at the angles typical for the joint of pre-existing and newly formed fractures. The study considers variations and coupling of fluid flow rates, proppant volumetric concentrations, fluid dynamic viscosities and fracture intersection angles. Proppants are widely used during hydraulic fracturing to keep fractures open and enhance reservoir permeability. This study uses plexiglas experimental slots and visual analysis for identifying particle displacements. Geo-Particle Image Velocimetry-ReliabilityGuided (GeoPIV-RG) method tracks particle movements among images by comparing the reference and subsequent snapshots at the point and time of interest. Results of this study show that the proppant volumetric concentration and the fluid flow rate are closely correlated with each other for affecting proppant flow, transport, and agglomeration formation. Increasing the proppant volumetric concentration generally promotes particle agglomeration, with different extent when coupled with the fluid flow rate. Proppant volumetric concentration affects the size, shape, and distribution of particle clusters. Increasing the fluid flow rate increases the occurrence of particle agglomerates at low proppant volumetric concentration; however, this trend is absent under high proppant volumetric concentrations. Sizes and shapes of proppant agglomerates change as the fluid flow rate changes. Changes of fracture intersection angle minimally affect shape, size and distance between proppant agglomerates and clusters. Furthermore, increasing the fluid dynamic viscosity strongly promotes proppant agglomeration. Although fluid dynamic viscosity changes do not affect the shape and size of particle clusters, the distance between adjacent clusters decreases at higher fluid dynamic viscosity.
\end{abstract}

Keywords Hydraulic Fracturing · Proppant and Particle Agglomeration · Fracture Intersection · Slot Experiments

\section{Literature review}

Particle agglomeration and clustering have been extensively studied for better understanding suspension behavior in chemistry and chemical engineering, but the research related to the flow and transport of proppant in realistically looking rock fractures in geo-reservoirs has been limited. Proppants are small particles used in the oil and gas industry and geothermal reservoirs during the hydraulic fracturing process. Proppants are placed into fractures by mixing and injecting

Wenpei Ma

w6ma@eng.ucsd.edu

Ingrid Tomac

itomac@ucsd.edu

1 Department of Structural Engineering, University of California-San Diego, 9500 Gilman Drive, La Jolla, San Diego, CA 92093, USA with later stages of fracturing fluid to prop the fractures after the hydraulic fracturing is done. Therefore, proppants help to enhance the permeability of fractured rock mass and improve the production. Although there are several experimental studies on particle clustering in fluid-particle flows (Guala et al. 2008; Saw et al. 2008; Fiabane et al. 2012), numerical simulations prevail (Ho and Sommerfeld 2002; Raiskinmäki et al. 2003; Bec et al. 2005; Gualtieri et al. 2009; Li et al. 2011; Gustavsson et al. 2014; Reeks 2014). Proppant flow and transport in hydraulic fractures have been investigated both experimentally and numerically (Zhang et al. 2007; Dayan et al. 2009; Sahai 2012; Wong et al. 2013; Sahai et al. 2014; Aimene and Ouenes, 2015; Alotaibi and Miskimins 2015; Li et al. 2016; Luo and Tomac 2018a; Luo and Tomac 2018b; Tong and Mohanty 2016; Wen et al. 2016; Zou et al. 2016; Chang et al. 2017; Kesireddy 2017; Kou et al. 2018; Pan et al. 2018; Fjaestad and Tomac 2019; Kumar and Ghassemi 2019; Sahai and Moghanloo 2019; 
Hampton et al. 2019; Nandlal and Weijermars 2019). However, only a limited number of studies have been performed on particle agglomerations during the proppant flow and transport in rock fractures (Eskin and Miller, 2008; Tomac and Gutierrez, 2014; Tomac and Gutierrez, 2015; Luo and Tomac, 2018a; Fernandez et al., 2019; Huang et al. 2019; Zhou et al., 2019).

Ho and Sommerfeld (2002) identified that particle agglomeration in turbulent flow within a collision cylinder, according to numerical models, can be described by stochastic collision model. Particle clusters are governed by collision efficiency and sticking potential due to particle geometry and size differences and van der Waals forces (Ho and Sommerfeld, 2002). Raiskinmäki (2003) studied shear flows of particulate suspension and found that clusters formed in the Couette flow can be divided into rotating chain-like clusters and particles layer at the channel wall. The size distribution of the rotating clusters is scale-invariant in the smallcluster regime and decreases rapidly above a characteristic length scale diverging at jamming transition (Raiskinmäki, 2003). In addition, the behavior of clusters can be divided into three categories based on Reynolds numbers (Raiskinmäki, 2003): When particle Reynolds number is less than 0.1 , particle clusters are mostly in a chain shape and the shape is controlled by viscosity and kinetic properties; for particle Reynolds number is around 1, particle clusters occur the most frequently and the kinematic properties are losing control of cluster shapes; for particle Reynolds number is larger than 10, clusters begin to separate due to inertial effects. Bec et al. (2005) studied clustering of heavy particles in laminar flow, where each layer moves smoothly relative to neighboring layers with almost no mixings, and concluded that inertia twofold enhances collision rates: when its correlation with particle positions is high and when velocity field is not differentiable. Bec et al., 2005 proposed a model that estimates the particle collision rates with different particle sizes. Guala et al. (2008) found experimentally that large particles tend to cluster in strain-dominated regions, where the normal strain component is more significant than the rotational component when calculating velocity gradient components. Preferential particle concentrations occur at scales comparable with the Taylor microscale, which is a length scale of turbulent flow. Taylor microscale (Taylor 1935) combines the effects of the kinematic viscosity of the fluid, the root-mean square of the velocity fluctuation, and the energy dissipation rate (Guala et al. 2008). Saw et al. (2008) showed an experimental evidence of spatial particle clusters with high inertia in the homogeneous, isotropic turbulent flow at high Taylor-scale Reynolds numbers (a non-dimensional global number that describes the degree of turbulence and considers spatial and temporal scales) regime, where Taylor-scale Reynolds number is between 440 and 660 . The dissipation-scale clustering becomes stronger as the fluid Stokes number increases, which is a non-dimensional number that compares relative particle inertial response time to Kolmogorov time (a time scale depends on fluid kinematic viscosity and turbulent kinetic energy dissipation rate); also, the dissipation-scale clustering shows similar trend when considering particle Stokes number (Saw et al. 2008). Gualtieri et al. (2009) did numerical simulations and concluded that the homogeneity of particle configurations in flow is broken by the interaction of local eddies. Fiabane et al. (2012) observed in experiments that neutrally buoyant particles cluster insignificantly, while heavy particles cluster a lot. Gustavsson et al. (2014) did a numerical simulation and find out that small particle clusters in incompressible random velocity fields may be strongly anisotropic and affected by gravity depending on particle Stokes number.

Generally, it has been established that proppants are not uniformly distributed in a fracture during flow and transport, and may form large vortexes across the fracture length where fluid turbulence will create multiple large spiral paths flowing in a reversed direction to flow direction due to the effect of various proppant settlement boundary shapes at the bottom (Eskin and Miller, 2008; Huang et al. 2019; Fernandez et al. 2019; Zhou et al. 2019). Investigations on effects of particle concentrations, fluid viscosity, fracture shape, and fracture roughness have been performed numerically and experimentally in the past (Tomac and Gutierrez, 2014; Tomac and Gutierrez, 2015; Luo and Tomac, 2018a). Tomac and Gutierrez (2015) found that the lubrication effect dramatically impacts particle motions when a combination of parameters is unfavorable. Lubrication forces in narrow fractures act upon particle-particle and particle-wall collisions and lead to particle agglomerations by decreasing the post-impact kinetic energy of particles. Adjacent particles stay together and form clumps, while fluid flows around clusters. As fluid viscosity and/or proppant concentration increases, agglomerations are more frequently observed. Luo and Tomac (2018a) confirmed the effects of lubrication forces experimentally and showed that proppant concentration and fluid viscosity enhance particle agglomerations in the fluid. Furthermore, wall effects at low particle diameterto-fracture width ratios have a strong effect on agglomeration and wall effect is enhanced on rough surfaces than the smooth surfaces (Luo and Tomac, 2018a).

The main goal of this paper is to investigate the effects of fracture intersection angle, fluid flow rate, proppant volumetric concentration, and fluid dynamic viscosity on the formation of particle agglomerations using Geo-Particle Image Velocimetry-Reliability-Guided (GeoPIV-RG) Method. Proppant clustering processes during flow and transport in realistic fractures have not yet been fully understood; therefore, this paper aims to address a gap in the literature considering coupled effects of fracture intersection angle and 
other relevant parameters like the fluid dynamic viscosity, the slurry flow rate, and the initial particle concentration. By employing a relatively new video analysis approach, namely the GeoPIV-RG Method, both quantitative and qualitative information about the proppant particle motion will be obtained. Furthermore, GeoPIV-RG provides a quantitative calculation of local and relative slurry velocity field in the fracture plane, which is an important factor to assess how actual slurry motion fluctuates within the fracture under different initial and boundary (injection point velocities) conditions.

\section{Methodology}

This research uses an experimental setup to investigate different factors on proppant agglomeration, including fracture intersection angle, proppant volumetric concentration, slurry flow rate, and fluid dynamic viscosity. In this section, we will discuss how we select materials and their combinations, set up the experimental components, record, and analyze the video footages, and handle errors (Ma et al., 2020).

\section{Material selection and experimental setup}

We use sieved Ottawa F65 sand with relatively uniform size distribution at 60/100 mesh (average particle diameter is $200 \mu \mathrm{m}$ ) as the only type of proppant in all the experiments. The main factors that are varied for investigating the formation of particle clusters include the proppant volumetric concentration, the slurry flow rate, the fluid dynamic viscosity, and the fracture intersection angle. Different volumetric combinations of water and glycerol generate Newtonian fluid with targeted dynamic fluid viscosities of $0.001 \mathrm{~Pa} \cdot \mathrm{s}, 0.005 \mathrm{~Pa} \cdot \mathrm{s}$, and $0.01 \mathrm{~Pa} \cdot \mathrm{s}$. Proppant volumetric concentrations are $10 \%$ and $20 \%$. Fracture intersection angles $30^{\circ}$ and $45^{\circ}$ are selected to present a realistic scenario as extracted from recent reservoir fracturing studies (Li et al. 2016; Pan et al. 2018; Frash et al. 2019). Figure 1a, b shows the top view and physical appearance of a $30^{\circ}$ intersection angle fracture. Slurry flow rates are controlled by pump motor frequencies at $10 \mathrm{~Hz}$ and $20 \mathrm{~Hz}$, which correspond to the measured slurry flow rates from 2.50 to $4.55 \mathrm{~L} / \mathrm{min}$. Note that slurry flow rate depends on the combination of the proppant volumetric concentration and the fluid dynamic viscosity. To calibrate the slurry flow rate, the effect of the proppant volumetric concentration and the fluid dynamic viscosity was investigated, and the limiting pump rotor frequency that avoids cavitation problem was determined. For proppant-fluid slurries, cavitation under the maximum proppant volumetric concentration occurs when the pump rotor frequency is higher than $25 \mathrm{~Hz}$, which also increases when the proppant volumetric concentration decreases. For a clean viscous fluid, the cavitation under maximum fluid dynamic viscosity occurs when pump rotor frequency is above $22 \mathrm{~Hz}$. Therefore, all the combinations of the fluid flow rate, the fluid dynamic viscosity, and the proppant volumetric concentration do not lead to cavitation. The measured flow rates for each combination are shown in Table 1. Table 2 summarizes experimental environments for all cases.

A storage bucket with a mixer seated in a high position allows the mixed particle-fluid slurry to flow down to the pump under gravity effects. Then, the fluid is pumped into a horizontal fracture (Figs. 2, 3a). Three cameras and
Fig. 1 a Top view and b photograph of the $30^{\circ}$ intersection angle fracture

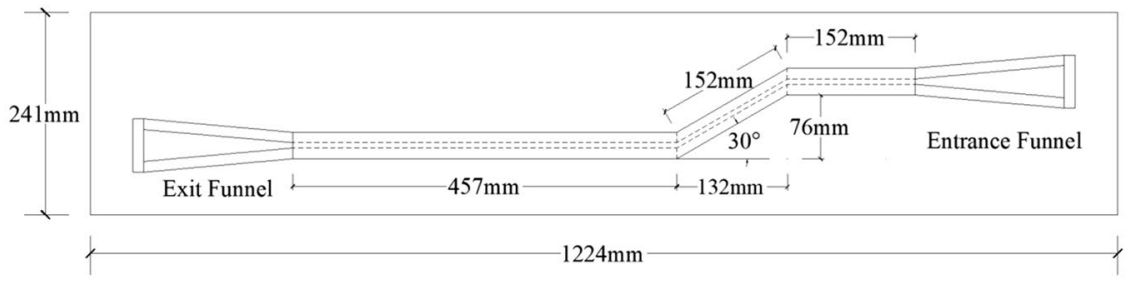

(a)

(b)

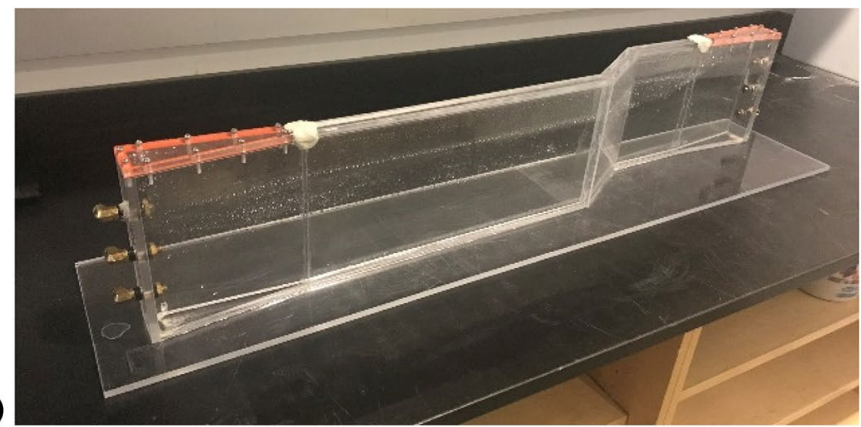


Table 1 Flow rates under all conditions

\begin{tabular}{llll}
\hline Viscosity $(\mathrm{Pa} \cdot \mathrm{s})$ & $\begin{array}{l}\text { Volumetric concen- } \\
\text { tration }(\%)\end{array}$ & $\begin{array}{l}\text { Frequency } \\
(\mathrm{Hz})\end{array}$ & $\begin{array}{l}\text { Flow rate } \\
(\mathrm{L} / \mathrm{min})\end{array}$ \\
\hline 0.001 & 10 & 10 & 3.90 \\
0.001 & 10 & 20 & 4.55 \\
0.001 & 20 & 10 & 3.30 \\
0.001 & 20 & 20 & 3.70 \\
0.005 & 10 & 10 & 3.35 \\
0.005 & 10 & 20 & 3.68 \\
0.005 & 20 & 10 & 2.55 \\
0.005 & 20 & 20 & 3.50 \\
0.010 & 10 & 10 & 2.50 \\
0.010 & 10 & 20 & 3.20 \\
0.010 & 20 & 10 & 2.65 \\
0.010 & 20 & 20 & 3.13 \\
\hline
\end{tabular}

two LED lights with 12,000 lumens are placed in front of the fracture in the left and right for enhancing light and minimizing shadow (Fig. 3b). The cameras are placed at a distance of $114 \mathrm{~cm}$ from the fracture front face.
The main camera used is the scientific high-resolution and high-speed PHANTOM C320. The videos were shot $1280 \times 1024$ pixels with 900 frames per second. The camera is focused to record the initial portion of the fracture immediately after the fracture intersection. A SONY DSCRX10M3 digital still camera records fluid-particle motion prior to the intersection, whose videos are competitively high in resolution but have lower speed: $1920 \times 1080$ pixels with 60 frames per second. A Nikon D160 digital camera records all fluid-particle motions after the intersection, overlaying with the PHANTOM camera. The quality of the videos was similar to the SONY camera, $1280 \times 720$ pixels 60 frames per second. The two low-speed cameras serve as a backup.

\section{GeoPIV-RG method}

Geo-Particle Image Velocimetry-Reliability-Guided (GeoPIV-RG) method is typically used for analyzing motions of granular materials. GeoPIV-RG is a Matlab code developed by Stainer et al. (2015), previously called GeoPIV by White and Take (2002). Figure 4 describes the main image processing in the GeoPIV-RG. Before running
Table 2 Parameters for all the experimental cases

\begin{tabular}{|c|c|c|c|c|c|}
\hline Test & $\begin{array}{l}\text { Fluid viscosity } \\
(\mathrm{Pa} \cdot \mathrm{s})\end{array}$ & $\begin{array}{l}\text { Volumetric concentra- } \\
\text { tion of sand }(\%)\end{array}$ & $\begin{array}{l}\text { Pump rotor fre- } \\
\text { quency }(\mathrm{Hz})\end{array}$ & $\begin{array}{l}\text { Fluid flow rate } \\
\text { (L/min) }\end{array}$ & $\begin{array}{l}\text { Fracture } \\
\text { intersection } \\
\text { angle }\end{array}$ \\
\hline 1 & 0.001 & 10 & 10 & 3.90 & 30 \\
\hline 2 & 0.001 & 10 & 10 & 3.90 & 45 \\
\hline 3 & 0.001 & 10 & 20 & 4.55 & 30 \\
\hline 4 & 0.001 & 10 & 20 & 4.55 & 45 \\
\hline 5 & 0.001 & 20 & 10 & 3.30 & 30 \\
\hline 6 & 0.001 & 20 & 10 & 3.30 & 45 \\
\hline 7 & 0.001 & 20 & 20 & 3.70 & 30 \\
\hline 8 & 0.001 & 20 & 20 & 3.70 & 45 \\
\hline 9 & 0.005 & 10 & 10 & 3.35 & 30 \\
\hline 10 & 0.005 & 10 & 10 & 3.35 & 45 \\
\hline 11 & 0.005 & 10 & 20 & 3.68 & 30 \\
\hline 12 & 0.005 & 10 & 20 & 3.68 & 45 \\
\hline 13 & 0.005 & 20 & 10 & 2.55 & 30 \\
\hline 14 & 0.005 & 20 & 10 & 2.55 & 45 \\
\hline 15 & 0.005 & 20 & 20 & 3.50 & 30 \\
\hline 16 & 0.005 & 20 & 20 & 3.50 & 45 \\
\hline 17 & 0.010 & 10 & 10 & 2.50 & 30 \\
\hline 18 & 0.010 & 10 & 10 & 2.50 & 45 \\
\hline 19 & 0.010 & 10 & 20 & 3.20 & 30 \\
\hline 20 & 0.010 & 10 & 20 & 3.20 & 45 \\
\hline 21 & 0.010 & 20 & 10 & 2.65 & 30 \\
\hline 22 & 0.010 & 20 & 10 & 2.65 & 45 \\
\hline 23 & 0.010 & 20 & 20 & 3.13 & 30 \\
\hline 24 & 0.010 & 20 & 20 & 3.13 & 45 \\
\hline
\end{tabular}

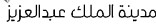
KACST 


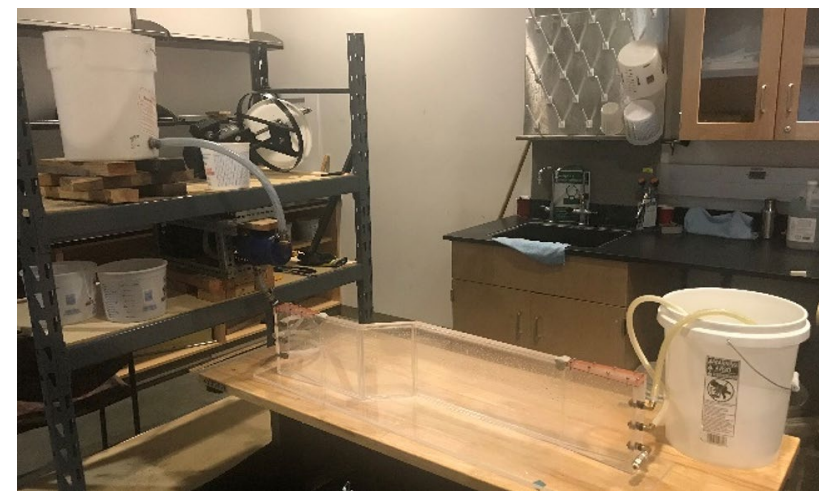

Fig. 2 Physical configuration of the experimental system

the main code, users should select the set of images to be analyzed, choose the region of interest within the selected images, and define mesh sizes and spacing. The main code tracks particle movements among images by comparing the reference and subsequent images at the point in time of interest. Both the leapfrog and sequential schemes help to provide a better result. The leapfrog method is good for experiments with no additionally marked control points and retains the initial reference image after each computation. The sequential schemes method updates the reference image after each computation, which effectively reduces wild results. Although the software directly yields the slurry velocity field, due to lack of additional markers on the fracture surface, we had to pause the software while generating displacement results in pixels. An additional post-processing converts results from displacement based to velocity based, as well as in $\mathrm{cm} / \mathrm{s}$.

\section{Error control}

Sources of errors in GeoPIV-RG analysis include the camera performance, the image and the video setup, the lighting condition, the setup of experimental components and the GeoPIV-RG software processing. The accuracy is also impacted by the image quality, the lighting condition, the image-particle diameter, spatial variation, recording angles, and mesh sizes (White and Take, 2002; Stanier et al. 2015;
Fig. 3 Schematic of the experimental setup, a profile view and b plan view

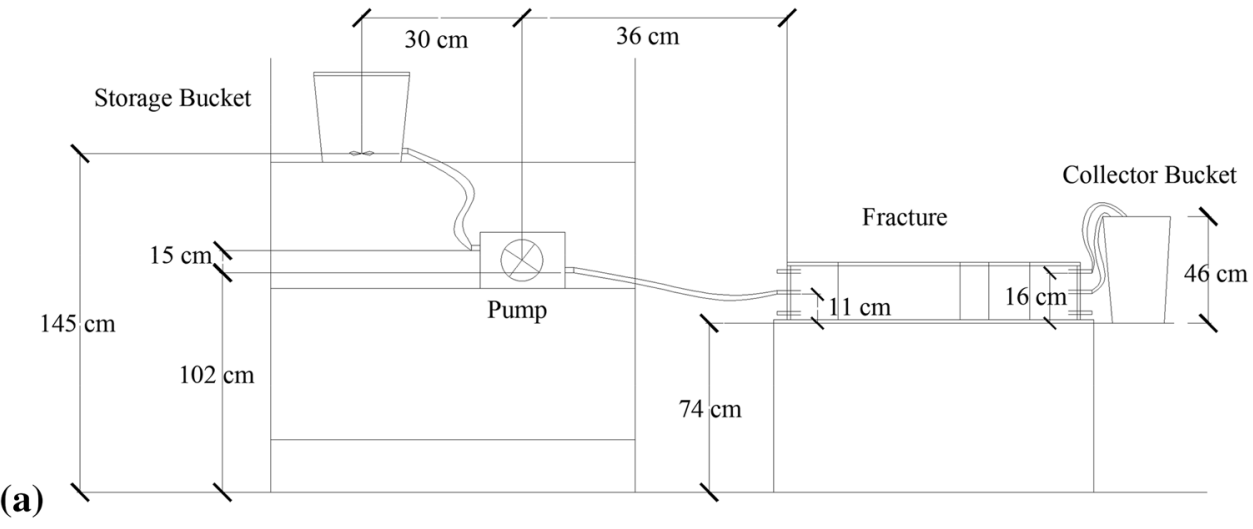

(a)

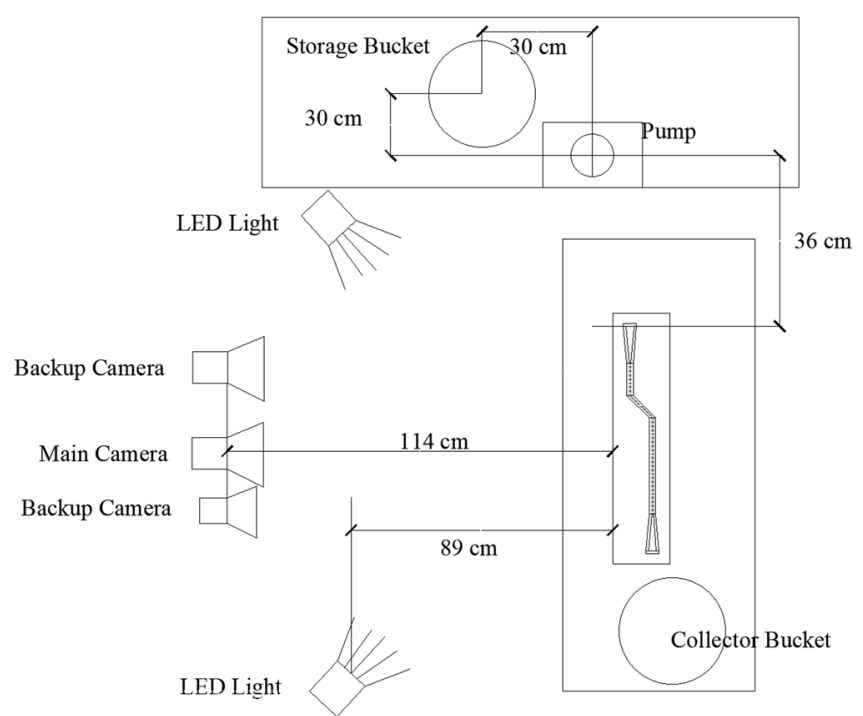

(b)

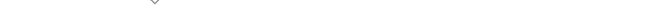


Fig. 4 Flow chart of GeoPIVRG software (White and Take, 2002)

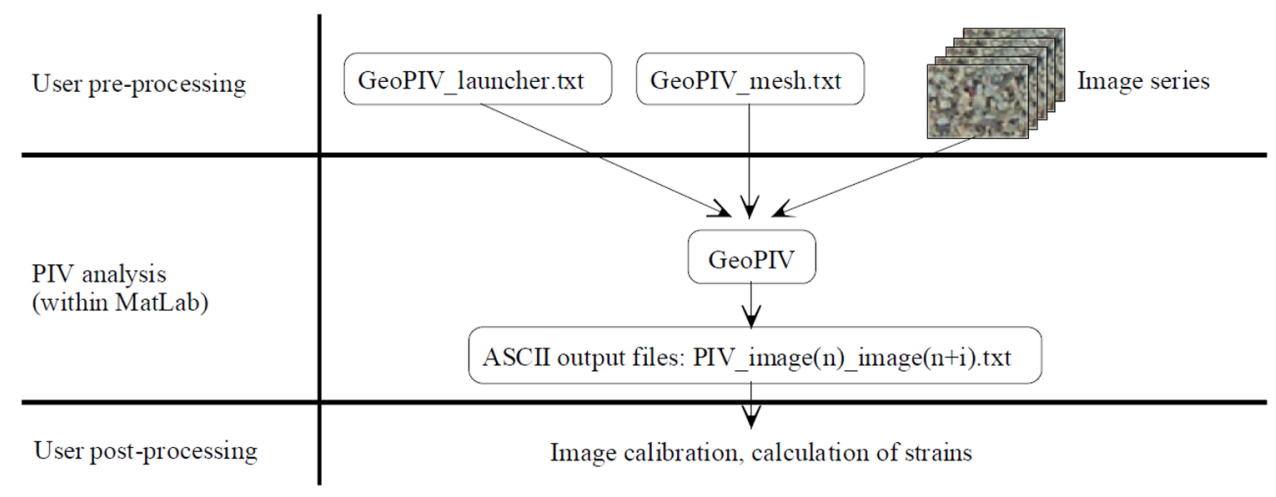

Luo and Tomac, 2018b; Fjaestad and Tomac, 2019; Ma et al. 2020). We developed standardized test procedures which include fixing the experiment, cameras, light, and controlling input parameters like the slurry flow rate and mixing. To avoid image distortion, the cameras are placed at the horizontal level same as the fracture and perpendicular to the fracture front face. Mesh selection is identified as the main parameter that affects the result precision. Smaller mesh sizes provide better local information while larger mesh sizes provide better precision (Stanier et al. 2015; Luo and Tomac, 2018b; Fjaestad and Tomac, 2019). To verify what mesh size and spacing are appropriate, four different mesh sizes were analyzed: $10 \times 10,20 \times 20,30 \times 30$, and $40 \times 40$ pixels. The first number is the mesh size, and the second number is the distance between the mesh centers in pixels. Two neighboring areas with similar velocity distributions are selected. The mean velocities for each selected region and mesh size are then compared. When fixing one specific region and comparing the effect of the mesh size, the error is larger than $10 \%$ between 10-pixels and 20-pixels meshes, while the error is as low as $2 \%$ between 20 -pixels and 30-pixels meshes, and between 30-pixels and 40-pixels. Therefore, 20-pixels meshes and above provide sufficient precision. When fixing one specific mesh size and comparing different regions, we found that the error is larger than $10 \%$ for 10 -pixels meshes, while less than $5 \%$ for 20 -pixels meshes and above. For better capturing of local information, we decide to select 20-pixels meshes for our analysis. The GeoPIV-RG software analysis is run repeatedly for each experiment at least three times. All the results yielded matching graphical results within matching velocity ranges, particle cluster shapes and sizes.

The accuracy criteria is defined so that the displacement resolution is smaller than the particle size. The average of the camera pixel used is $10 \mu \mathrm{m}$, being 20 times smaller than the average particle diameter of $200 \mu \mathrm{m}$. For the $2 \%$ error considered for mesh size effects, the error in obtained slurry velocity is $0.17 \mathrm{~cm} / \mathrm{s}$, which gives a total displacement of $18 \mu \mathrm{m}$ for 10 frames of pictures within $0.01 \mathrm{~s}$. For the $5 \%$ error considered for regional effects, the velocity difference is $0.35 \mathrm{~cm} / \mathrm{s}$, which leads to a total displacement of $38 \mu \mathrm{m}$ for 10 frames of pictures within $0.01 \mathrm{~s}$. Therefore, it can be concluded that displacement errors are small comparing with the particle size.

\section{Results}

\section{Visual and GeoPIV-RG analysis of proppant slurry flow and transport}

The results of visual observation are obtained from video footage snapshots. Particle agglomeration mechanisms are barely visible in the original color pictures. Although we applied picture filtering and editing methods to enhance the contrast between particles and the surrounding background, the visual examination cannot distinct observable agglomerations in most of the experiments. Figure 5a shows a snapshot of hardly observable agglomeration for experiment 23 under $30^{\circ}$ intersection fracture, $0.01 \mathrm{~Pa} \cdot \mathrm{s}, 10 \%$ proppant volumetric concentration and $3.13 \mathrm{~L} / \mathrm{min}$ flow rate, which is representing for most of the experiments. Figure $5 \mathrm{~b} \mathrm{dem}$ onstrates a snapshot of clearly observable agglomeration for experiment 22 under $45^{\circ}$ intersection fracture, $0.01 \mathrm{~Pa} \cdot \mathrm{s}$, $20 \%$ proppant volumetric concentration and $2.65 \mathrm{~L} / \mathrm{min}$ flow rate.

Therefore, the visual inspection is unhelpful for identifying particle agglomerations despite good quality images. However, GeoPIV-RG analysis of the high-resolution highspeed camera recordings provides detailed information on the microscopic scale. GeoPIV-RG captures differences at the pixel level within a series of images.

Table 3 summarizes particle agglomeration phenomena from the GeoPIV-RG and video results. Videos, as denoted in the last part in Table 3, generally have the appearance as shown in Fig. 5. Table 3 shows minor disparities in agglomeration quantity assessment between visualization and the GeoPIV-RG analysis. For example, GeoPIV-RG results yielded 3 experiments with "Plenty" of agglomerates, 13 
Fig. 5 a Experiment without observable agglomerations; $\mathbf{b}$ experiment with some observable particle clusters (a)

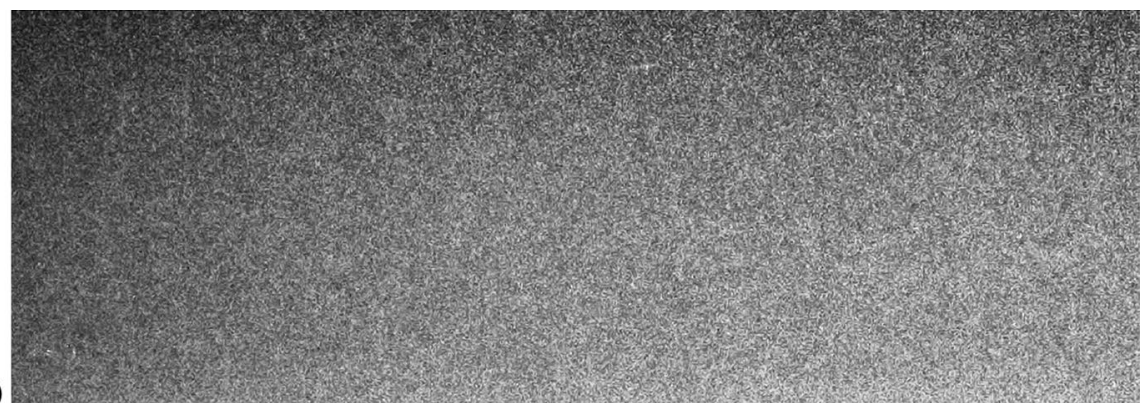

(b)

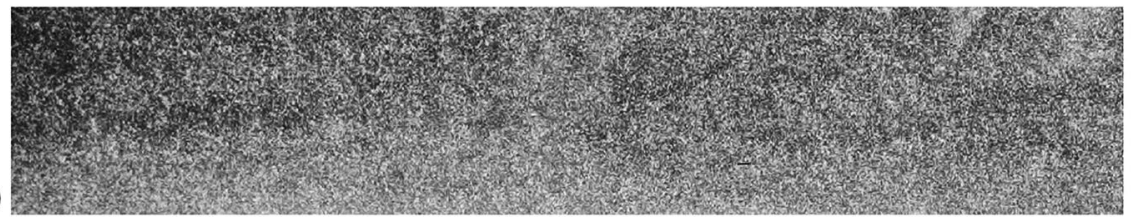

Table 3 Particle agglomeration summary of observations and the GeoPIV-RG results

\begin{tabular}{|c|c|c|c|c|c|c|c|}
\hline \multirow[t]{2}{*}{ EXP } & \multicolumn{3}{|c|}{ GeoPIV-RG results } & \multicolumn{4}{|c|}{ Video results } \\
\hline & exist & Obvious & Quantity & Exist & Obvious & Quantity & Other \\
\hline 1 & Yes & Medium & Only a few & Yes & Medium & Medium & \\
\hline 2 & Yes & Clear & Medium & Yes & Not Clear & Only a few & \\
\hline 3 & Yes & Medium & Medium & Yes & Not Clear & Only a few & \\
\hline 4 & Yes & Clear & Medium & Yes & Medium & Only a few & \\
\hline 5 & Yes & Clear & Medium & Yes & Medium & Medium & \\
\hline 6 & Yes & Not Clear & Only a few & Yes & Not Clear & Only a few & \\
\hline 7 & Yes & Clear & Medium & Yes & Medium & Medium & Lightly Layered \\
\hline 8 & Yes & Clear & Only a few & Yes & Medium & Medium & Lightly Layered \\
\hline 9 & Yes & Medium & Medium & Yes & Not Clear & Medium & \\
\hline 10 & Yes & Medium & Medium & Yes & Not Clear & Medium & \\
\hline 11 & Yes & Not Clear & Only a few & Yes & Not Clear & Medium & \\
\hline 12 & Yes & Not Clear & Only a few & Yes & Not Clear & Medium & Lightly Layered \\
\hline 13 & Yes & Not Clear & Only a few & Yes & Medium & Medium & \\
\hline 14 & Yes & Clear & Medium & Yes & Medium & Medium & Lightly Layered \\
\hline 15 & Yes & Clear & Medium & Yes & Medium & Medium & Lightly Layered \\
\hline 16 & Yes & Clear & Only a few & Yes & Not Clear & Medium & Lightly Layered \\
\hline 17 & Yes & Not Clear & Only a few & Yes & Medium & Medium & Layered \\
\hline 18 & Yes & Medium & Plenty & Yes & Not Clear & Medium & Layered \\
\hline 19 & Yes & Clear & Plenty & Yes & Not Clear & Medium & Lightly Layered \\
\hline 20 & Yes & Clear & Medium & Yes & Not Clear & Medium & Lightly Layered \\
\hline 21 & Yes & Clear & Plenty & Yes & Medium & Medium & Layered \\
\hline 22 & Yes & Clear & Medium & Yes & Medium & Medium & Layered \\
\hline 23 & Yes & Clear & Medium & Yes & Medium & Medium & Layered \\
\hline 24 & Yes & Clear & Medium & Yes & Medium & Medium & Layered \\
\hline
\end{tabular}

experiments with "Medium" agglomerates, 8 experiments with "Only a few" agglomerates. Visual observation yielded 20 experiments with "Medium" quantities of agglomerates, and 4 experiments with "Only a few" agglomerates.

Selected experiments analyzed in this paper are highlighted with blue boxes. The majority of the experiments selected for further analysis, No. 18, 20, 22, 23 and 24 use high dynamic viscosity carrying fluid (No. 17-24). We use these 5 experiments to study the effect of slurry flow rate, proppant volumetric concentration, and fracture intersection angle, because high fluid dynamic viscosity experiments carry proppant clusters over the entire camera-captured region. For analyzing the effect of the carrying fluid dynamic viscosity (No. 8, 16, 24), we fix the environment under high 
proppant volumetric concentration, high flow rate, and high intersection angle. Although we have the option of 8 different sets of experiments, not every set provides ideal data. The decisive experiment of each set depends on the one under the lowest fluid dynamic viscosity. In our case, experiment 8 has the best visual data; therefore, this experiment set is selected, and the fixing environment is considered.

\section{Effect of the proppant concentration}

Effect of proppant concentration is studied on two sets of experiments: No. 18 vs 22 (Figs. 6a, b) and No. 20 vs 24 (Figs. 7a, b). This chapter analyzes the effect of proppant volumetric concentration under different slurry flow rates. Figure $6 \mathrm{a}-\mathrm{b}$ shows slurry velocity analyzed with GeoPIVRG for experiments under $45^{\circ}$ fracture intersection angle, $0.01 \mathrm{~Pa} \cdot \mathrm{s}$ viscosity, low flow rate $(2.60 \mathrm{~L} / \mathrm{min})$, and with $10 \%$ and $20 \%$ proppant volumetric concentrations. Figure $7 \mathrm{a}, \mathrm{b}$ shows agglomerations of the slurry flowing under the same conditions as in Figs. 6a, b, but under a high flow rate $(3.15 \mathrm{~L} / \mathrm{min})$. Figures $6 \mathrm{a}, \mathrm{b}, 7 \mathrm{a}, \mathrm{b}$ show colored plots of the slurry velocity field, with warm colors denoting higher velocities defined in the color-legend on the right side. Therefore, groups of particles which flow adjacent to each other and which exhibit similar velocity fields can be recognized and identified as flowing particle clusters. Sizes and shapes of particle clusters can be partially recognized using the GeoPIV-RG method, since the video records a two-dimensional plane at the front of the fracture. Nevertheless, GeoPIV-RG enables a better understanding of the level and the character of particle agglomerations in a relatively narrow planar fracture, where the three-dimensional effects of slurry motions across the fracture width are not dominant. Comparing Figs. $6 \mathrm{a}$ and $7 \mathrm{a}$, qualitative differences in particle clusters size and shape are visible for lower initial $10 \%$ particle volumetric concentrations. A slower flow rate at $2.60 \mathrm{~L} / \mathrm{min}$ causes larger elongated clusters toward the fracture bottom, while the faster flow rates at $3.15 \mathrm{~L} / \mathrm{min}$ cause
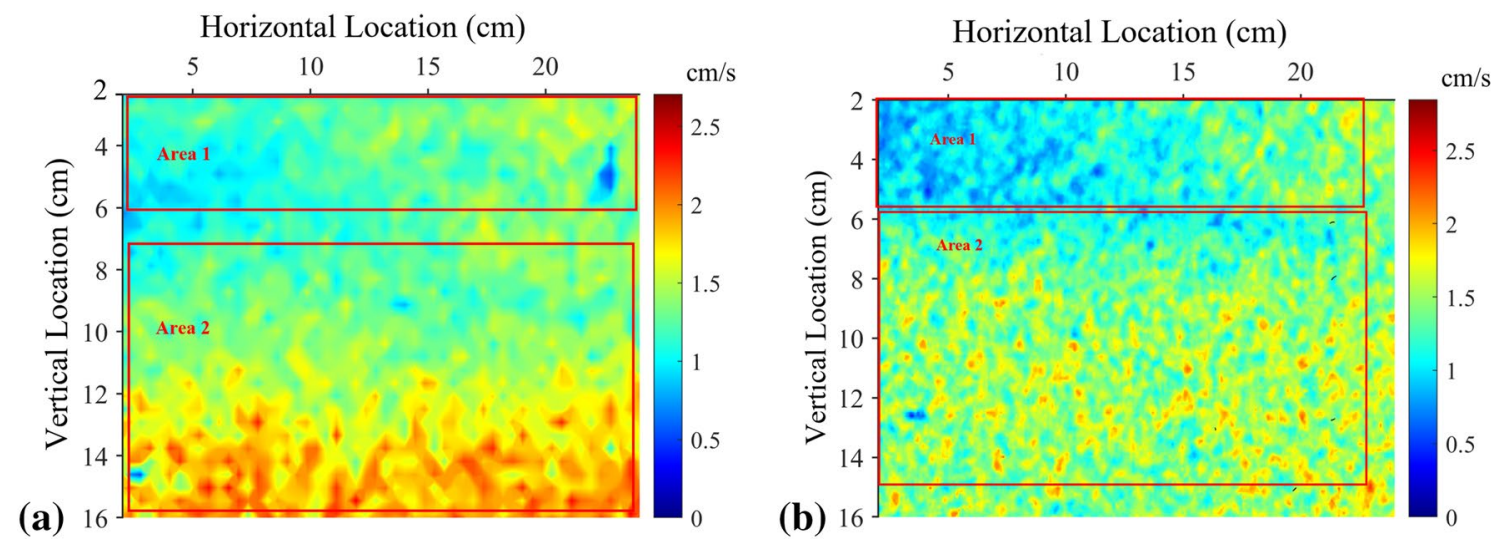

Fig. 6 Slurry velocity with GeoPIV-RG method in the region after $45^{\circ}$ fracture intersection, $0.01 \mathrm{~Pa} \cdot \mathrm{s}$ viscosity, low flow rate of $2.60 \mathrm{~L} / \mathrm{min}$, with a low initial proppant volumetric concentration of $10 \%$ and b) high initial proppant volumetric concentration of $20 \%$
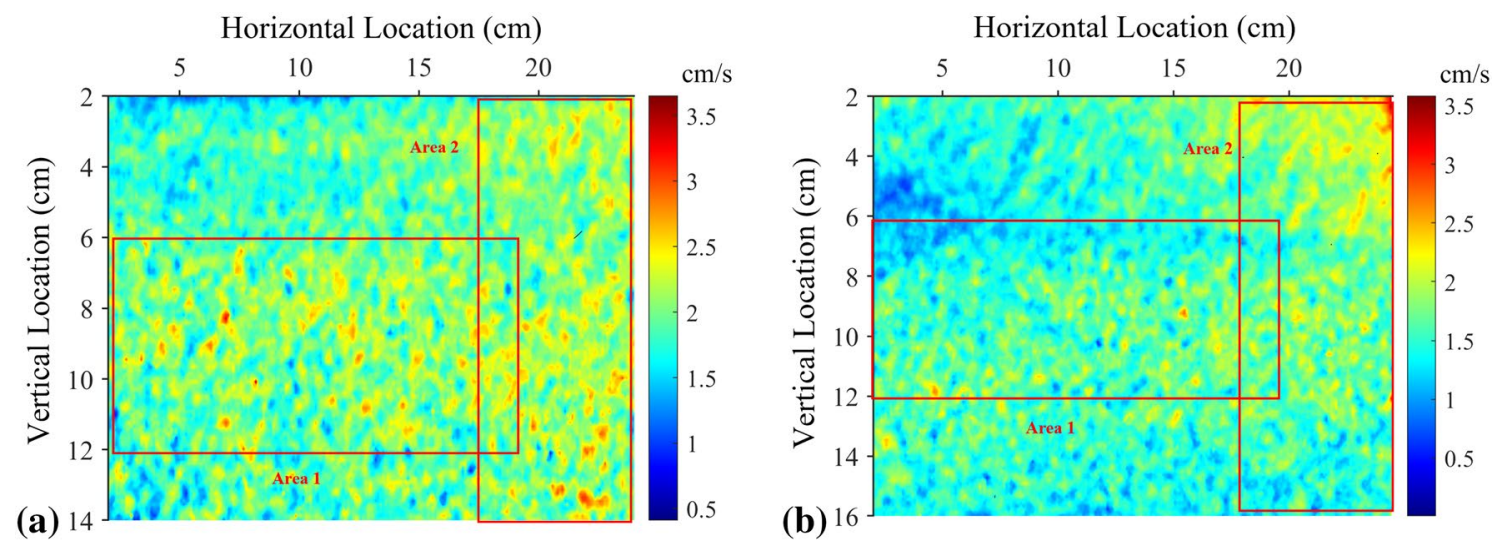

Fig. 7 Slurry velocity with GeoPIV-RG method in the region after $45^{\circ}$ fracture intersection, $0.01 \mathrm{~Pa} \cdot \mathrm{s}$ viscosity, high flow rate at $3.15 \mathrm{~L} / \mathrm{min}$, with a low initial proppant volumetric concentration of $10 \%$ and $\mathbf{b}$ high initial proppant volumetric concentration of $20 \%$ 
smaller, suspended particle clusters. As the initial particle volumetric concentration increases to $20 \%$ in Figs. $6 \mathrm{~b}$ and $7 \mathrm{~b}$, particle clusters become smaller, more rounded, more frequent and the flow rate difference between $2.60 \mathrm{~L} / \mathrm{min}$ and $3.15 \mathrm{~L} / \mathrm{min}$ hardly impacts the clustering phenomena. Frames in Figs. 6a-b and 7a-b denote different areas of interest, which are further analyzed with GeoPIV-RG method to better understand clustering phenomena at the bottom and top zones in a fracture in the case of Fig. 6a-b and middle and end sections in the case of Figs. 7a-b. For Figs. 6a-b, we categorize these subzones since there are enough horizontal trends. For Figs. 7a-b, we categorize these subzones since the horizontal trend is not clear enough, and we only select parts of the image with enough velocity contracts. Areas 1 and 2 correspond to different zones in sediment transport, dissolved load region and suspended load region, respectively, which are also present in slot flow experiments.

Figure $8 \mathrm{a}-\mathrm{b}$ focuses on Area 1 as the top region of the selected experiments in Fig. 6. Suspended slurry layers are prone to forming particle clusters across concentrations and different velocity ranges. For blue regions at both $10 \%$ and $20 \%$ initial volumetric concentrations, clustering can be seen, where the size of clusters appears to be larger with a smaller number at lower initial particle volumetric concentrations. When looking at lower regions of Figs. $6 a-b$, as shown in Figs. 9a-b, lower volumetric concentrations also yield larger, more separated agglomerates. For the $20 \%$ initial volumetric concentration in Fig. 9b, particle agglomerates more frequently, forming smaller, more rounded and regularly shaped particle clusters, in greater number and more uniformly suspended across the observed fracture area height than for the $10 \%$ initial volumetric particle concentration in Fig. 9a.

Figure 10a, $b$ focuses on the left regions of the selected experiments in Figs. 7a-b. Figure 11a, b focuses on the right regions of the selected experiments in Figs. 7a, b. Particle clusters in images from relatively higher flow rates of 3.15 L/min show a similar level of agglomerations across different particle volumetric concentrations. Closer observation reveals that particle cluster shapes are irregular and vary (a)

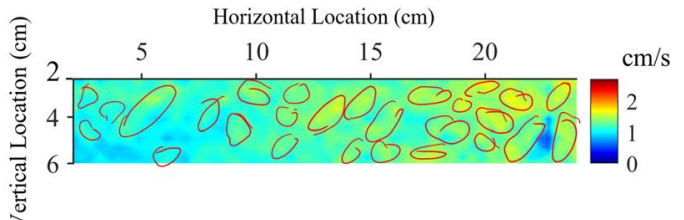

Fig. 8 Top region from a Fig. 6 a at $10 \%$ initial particle volumetric concentration, b Fig. 6 b at $20 \%$ initial particle volumetric concentration

(a)

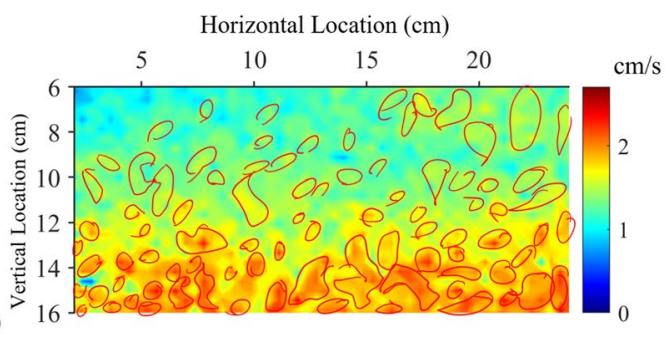

(b)

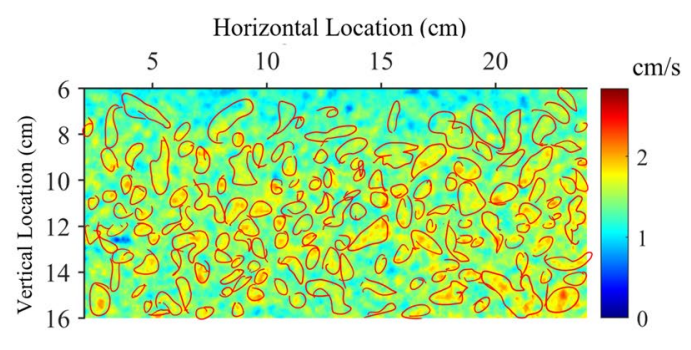

Fig. 9 Bottom region from a Fig. 6a at $10 \%$ initial particle volumetric concentration, b Fig. $6 \mathrm{~b}$ at $20 \%$ initial particle volumetric concentration

(a)

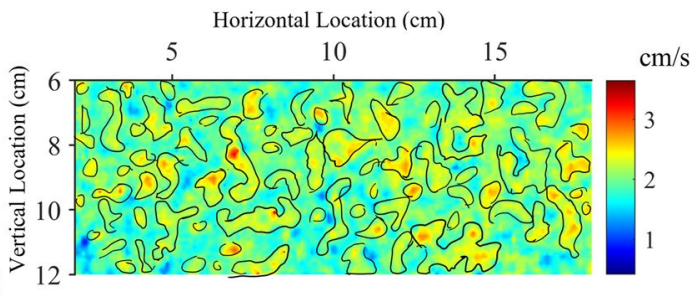

(b)

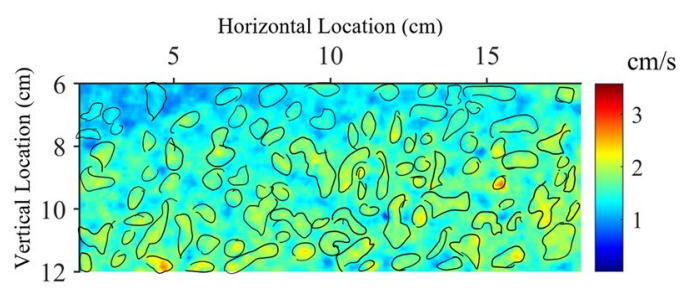

Fig. 10 Left region from a Fig. 7a at 10\% initial particle volumetric concentration, b Fig. $7 \mathrm{~b}$ at $20 \%$ initial particle volumetric concentration 


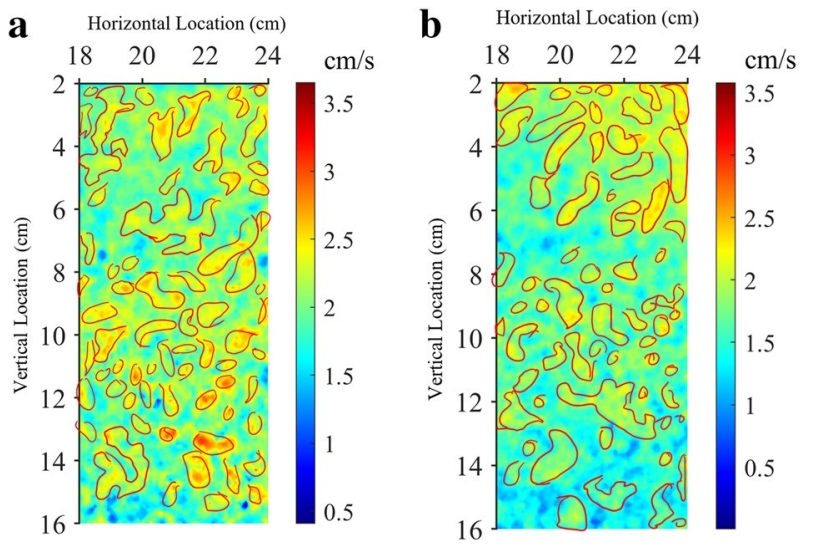

Fig. 11 Right region from a Fig. 7a at $10 \%$ initial particle volumetric concentration, b Fig. $7 \mathrm{~b}$ at $20 \%$ initial particle volumetric concentration

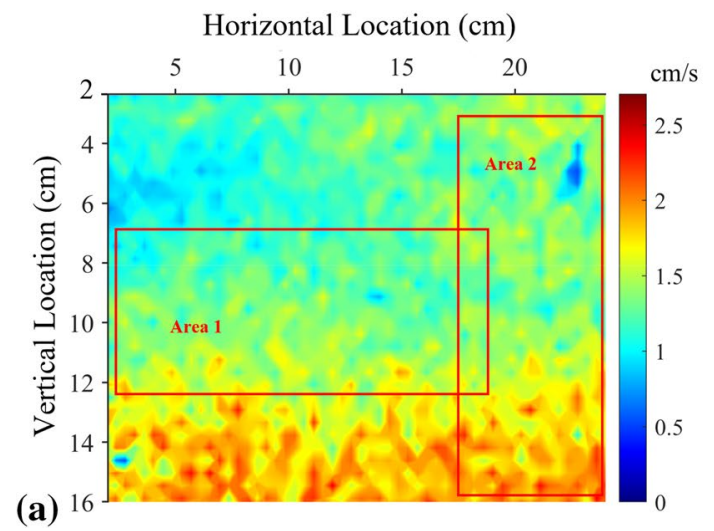

from small to large sizes, where different sizes are uniformly scattered across the fracture height at both $10 \%$ and $20 \%$ initial particle volumetric concentrations. Although proppant volumetric concentration promotes particle agglomerations under high flow rates, the effect of the increasing particle volumetric concentration is stronger under a low flow rate condition.

\section{Effect of the slurry flow rate}

Effects of the slurry flow rate during pumping into a fracture are closely studied on experiments No. 18 vs 20 (Figs. 12a-b) and No. 22 vs 24 (Figs. 13a-b). Figure $12 \mathrm{a}-\mathrm{b}$ shows slurry velocity with GeoPIV-RG method for experiments under $45^{\circ}$ fracture intersection angle, $0.01 \mathrm{~Pa} \cdot \mathrm{s}$ viscosity, low proppant volumetric concentration $10 \%$, with fluid flow rates between $2.5 \mathrm{~L} / \mathrm{min}$ and $3.2 \mathrm{~L} / \mathrm{min}$. Figure $13 \mathrm{a}-\mathrm{b}$ shows agglomerations of the slurry flowing under similar conditions at $45^{\circ}$ fracture,

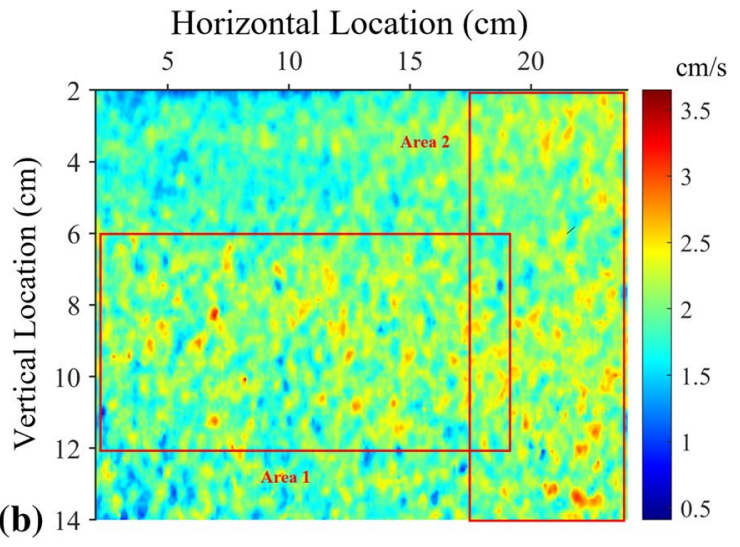

Fig. 12 Slurry velocity with PIV method under $45^{\circ}$ fracture intersection angle, $0.01 \mathrm{~Pa} \cdot \mathrm{s}$ viscosity, low proppant concentration $10 \%$, with a low flow rate $(2.5 \mathrm{~L} / \mathrm{min})$ and $\mathbf{b})$ high flow rate $(3.2 \mathrm{~L} / \mathrm{min})$
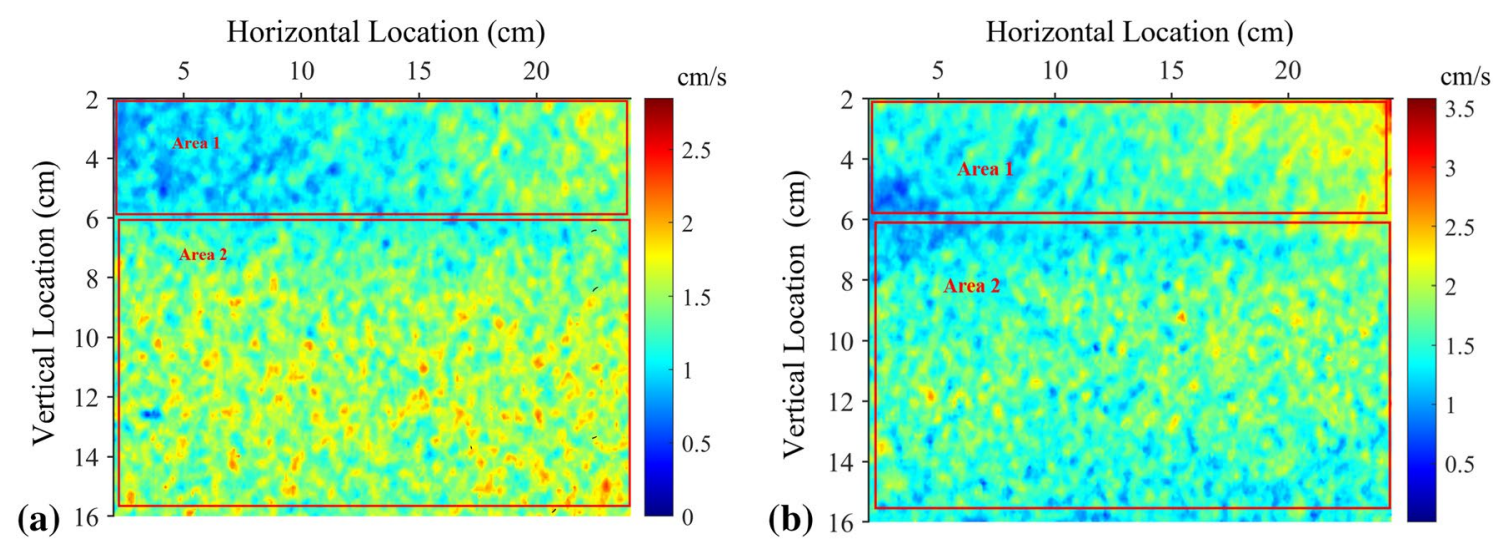

Fig. 13 Slurry velocity with PIV method under $45^{\circ}$ fracture intersection angle, $0.01 \mathrm{~Pa} \cdot \mathrm{s}$ viscosity, high proppant concentration $20 \%$, with a low flow rate $(2.65 \mathrm{~L} / \mathrm{min})$ and $\mathbf{b}$ high flow rate $(3.15 \mathrm{~L} / \mathrm{min})$ 
$0.01 \mathrm{~Pa} \cdot \mathrm{s}$ viscosity, $2.65 \mathrm{~L} / \mathrm{min}$ and $3.15 \mathrm{~L} / \mathrm{min}$ flow rates as in Figs. 12a-b, but under a higher proppant volumetric concentration of $20 \%$. Warmer colors in the images have higher particle flow velocities. Therefore, we can easily identify flowing particle clusters by particle groups close to each other with similar velocities. GeoPIV-RG method captures sizes and shapes of particle groups when studying the effect of slurry flow rate. Comparing Figs. 12a and $13 \mathrm{a}$, the differences in sizes and shapes of particle clusters for lower flow rates are clear $(2.5$ to $2.65 \mathrm{~L} / \mathrm{min})$ at different proppant volumetric concentrations. Lower proppant volumetric concentration causes particle clusters to be longer and larger, gathering around the bottom. Higher proppant volumetric concentration shapes particle clusters smaller and rounder, spreading those clusters all around the fracture. Under higher slurry flow rates $(3.15$ to $3.2 \mathrm{~L} /$ $\mathrm{min}$ ) and different proppant volumetric concentrations, as in Figs. 12b and 13b, particle clusters are broken into even smaller and rounder shapes. Proppant volumetric concentration plays a less significant role. Frames in Figs. 12a-b and 13a-b show different areas of interest, which will be discussed later in this section. Since we have the same four experiment (No. 18, 20, 22, 24) as previous section and we are only viewing them differently, the same reason how we select the subzones is also applied in this section. Areas 1 and 2 correspond to different zones which we will further discuss in this section.

Figure 14a-b focuses on Area 1, the left region, of the experiments in Fig. 12. Under low proppant volumetric concentration, increasing flow rate significantly increases the appearance of particle clusters. A higher flow rate tends to break up larger particle clusters into smaller ones at a closer distance, which makes the general shape more complex due to this closer distance. Figure 15a-b focuses on Area 2, the right region, of the experiments in Fig. 12. The role of flow rate observed in Area 1 still holds in Area 2.

Figure 16a-b focuses on Area 1, the top region, of the experiments in Figs. 13a-b. Figure 17a-b focuses on Area 2, the bottom region, of the experiments in Figs. 13a-b. Unlike under $10 \%$ proppant volumetric concentration, slurry flow rate does not play a strong role in forming
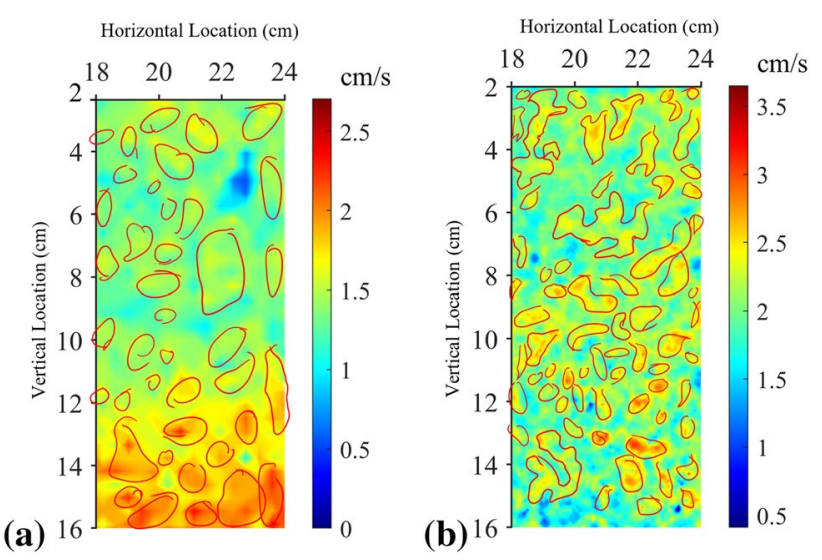

Fig. 15 Right region from a Fig. 12a at lower fluid flow rate, b Fig. $12 \mathrm{~b}$ at higher fluid flow rate

the size and shape of particle clusters under $20 \%$ proppant volumetric concentration environment, especially for the bottom part (Area 2). Flow rate separates the distance among particle clusters a little bit under high proppant concentration conditions.

\section{Effect of the fracture intersection angle}

Fracture intersection angle effect on particle agglomerations is investigated in experiments No. 23 vs 24 (Figs. 18a-b). Figure 18a-b shows slurry velocity with GeoPIV-RG method for experiments under $0.01 \mathrm{~Pa} \cdot \mathrm{s}$ viscosity, $20 \%$ volumetric concentration, high flow rate at $3.13 \mathrm{~L} / \mathrm{min}$, with different intersection angles of $30^{\circ}$ and $45^{\circ}$. For most of the areas, fracture intersection angle does not affect the size and shape of particle clusters. In both experiments, clusters appear small-to-medium, mostly rounded with some elongated shapes, and moderately spatially distributed in fractures. The only different part is at the very top of the fracture: for the smaller fracture intersection angle, the groups of clusters are elongated and inclined to the right. Areas 1 and 2 correspond to different zones, which we will further discuss in this section.

Figure 19a-b focuses on Area 1, the top region, of the experiments in Figs. 18a-b. Lower fracture intersection angle causes

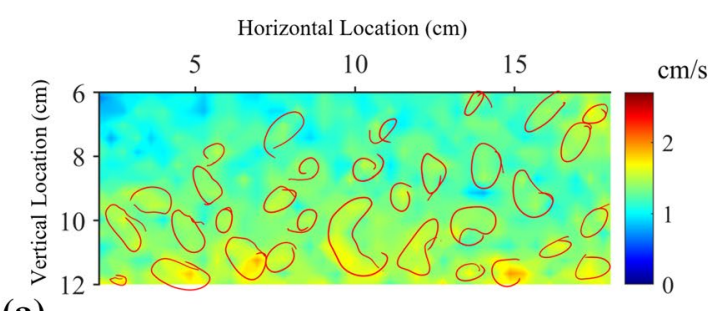

(a)

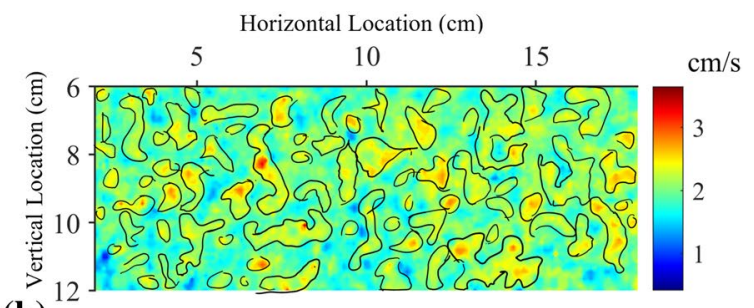

(b)

Fig. 14 Left region from a Fig. 12a at lower fluid flow rate; b Fig. 12b at higher fluid flow rate 
(a)

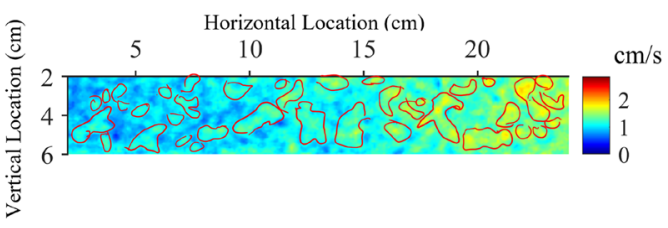

(b)

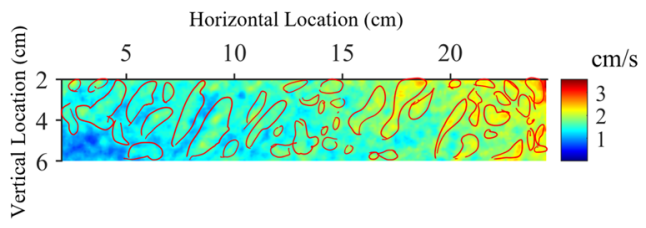

Fig. 16 Top region from a Fig. 13a at lower fluid flow rate, b Fig. 13b at higher fluid flow rate

(a)

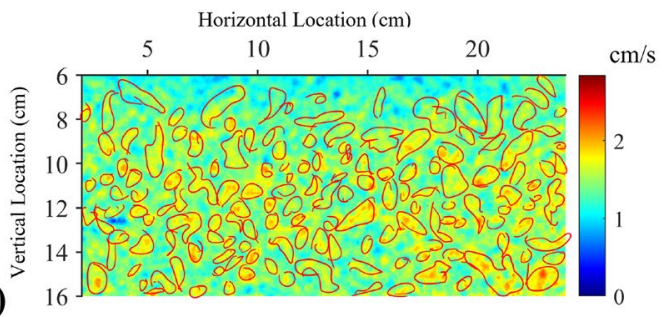

(b)

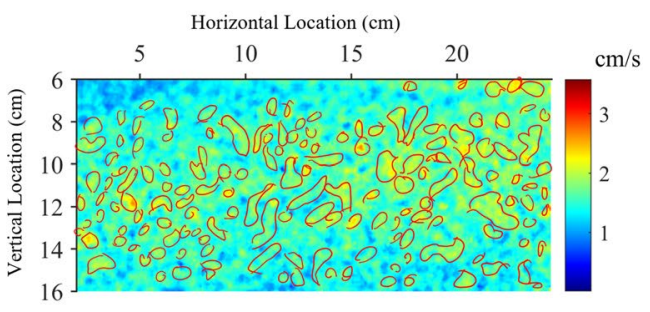

Fig. 17 Bottom region from a Fig. 13a at lower fluid flow rate, b Fig. 13b at higher fluid flow rate

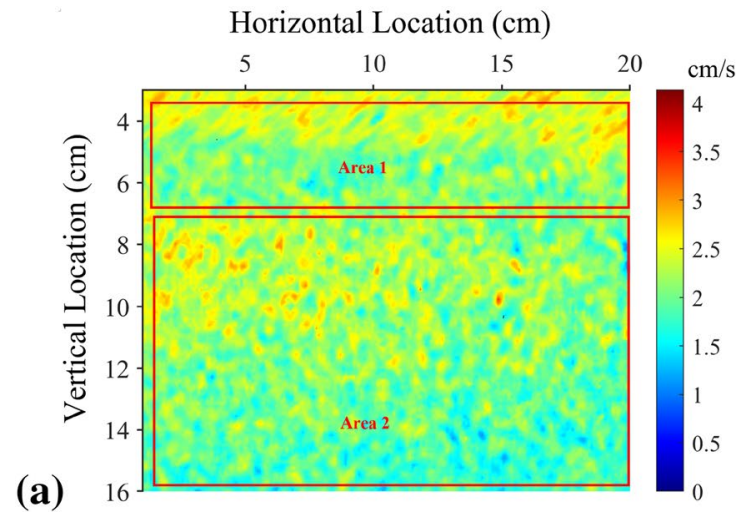

(b)

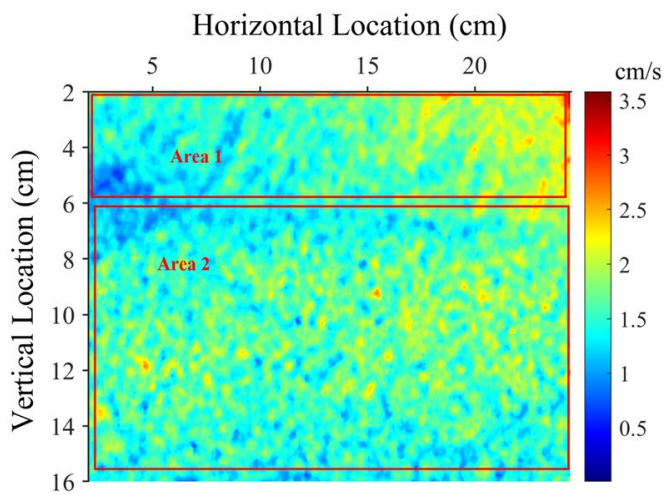

Fig. 18 Slurry velocity with PIV method under 0.01 Pas viscosity, high proppant concentration $20 \%$, high flow rate $3.15 \mathrm{~L} / \mathrm{min}$, with a $30^{\circ}$ fracture intersection and $\mathbf{b} 45^{\circ}$ fracture intersection angles

(a)

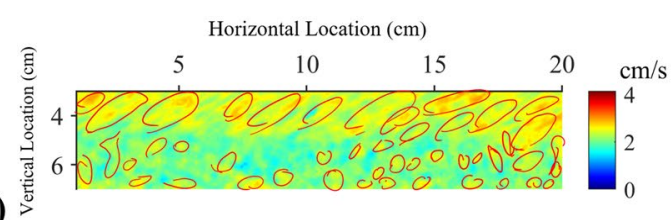

(b)

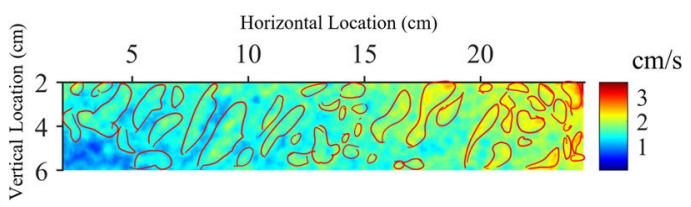

Fig. 19 Top region from a Fig. $18 \mathrm{a}$ at $30^{\circ}$ fracture intersection angle, b Fig. $18 \mathrm{~b}$ at $45^{\circ}$ fracture intersection angle

particle clusters more inclined to the right. The shapes are rounded and elongated under both fracture intersection angles. The distances of particle clusters are moderately separated for both fractures. Figure 20a-b focuses on Area 2, the bottom region, of the experiments in Figs. 18a-b. For this region, the effect of fracture intersection angle is even less significant. We barely see any differences in sizes, shapes, and spacing of particle clusters. The effect of fracture intersection angle itself on particle agglomerations does not couple with other effects significantly.

\section{Effect of the fluid dynamic viscosity}

The effect of the fluid dynamic viscosity is studied on three experiments in this section, No. 08, 16, and 24 (Figs. 21ac). Figure 21 a shows the slurry velocity under $45^{\circ}$ fracture 
(a)

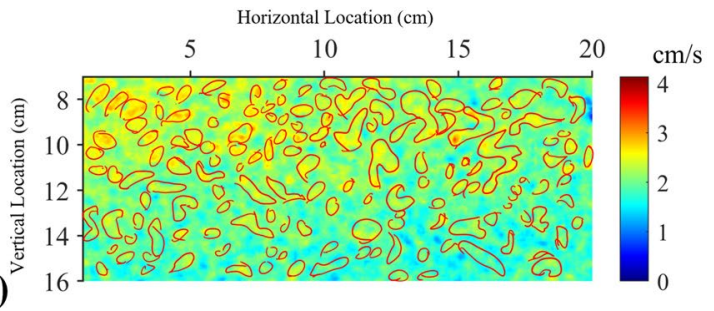

(b)

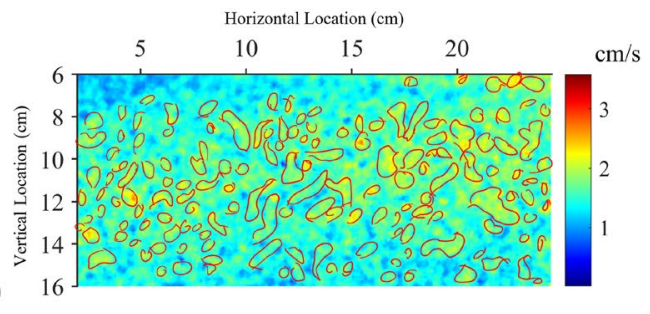

Fig. 20 Bottom region from a Fig. $18 \mathrm{a}$ at $30^{\circ}$ fracture intersection angle, b Fig. $18 \mathrm{~b}$ at $45^{\circ}$ fracture intersection angle

(a)

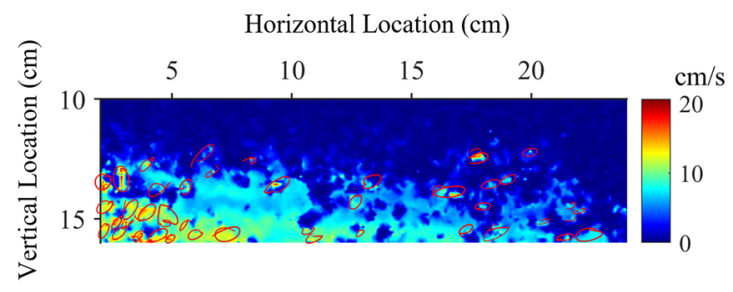

(b)

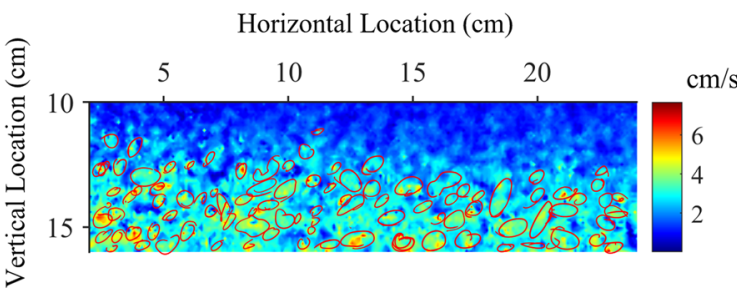

(c)

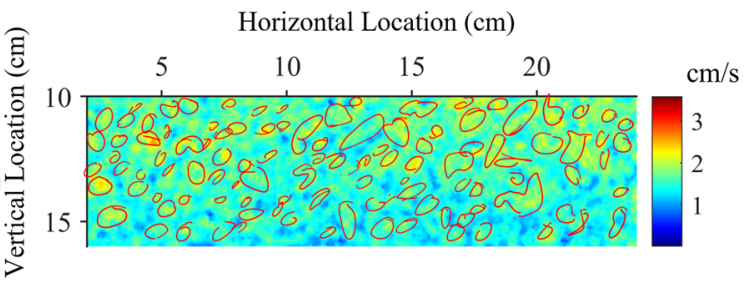

Fig. 21 Slurry velocity with GeoPIV-RG under high proppant concentration $20 \%$, high flow rate $3.5 \mathrm{~L} / \mathrm{min}$ in average, $45^{\circ}$ fracture intersection angle, with a $0.001 \mathrm{~Pa} \cdot \mathrm{s}, \mathbf{b} 0.005 \mathrm{~Pa} \cdot \mathrm{s}$ and c $0.01 \mathrm{~Pa} \cdot \mathrm{s}$ fluid dynamic viscosity

intersection angle, 20\% proppant volumetric concentration, high flow rate with $20 \mathrm{~Hz}$ pump rotor frequency equivalent to $3.70 \mathrm{~L} / \mathrm{min}$, and $0.001 \mathrm{~Pa} \cdot \mathrm{s}$ fluid dynamic viscosity. Figure $21 \mathrm{~b}$ shows slurry velocity under the same condition but for $0.005 \mathrm{~Pa} \cdot \mathrm{s}$ viscosity, noting that $20 \mathrm{~Hz}$ pump rotor frequency generates $3.50 \mathrm{~L} / \mathrm{min}$ flow rate because of the elevated fluid dynamic viscosity. Figure 21c shows slurry velocity for $0.01 \mathrm{~Pa} \cdot \mathrm{s}$ fluid, noting that $20 \mathrm{~Hz}$ pump rotor frequency generates only $3.13 \mathrm{~L} / \mathrm{min}$ flow rate. The bottom region for this set of experiments is of interest since proppant flows and settles significantly and particles are mostly absent from the top and middle parts at the lowest fluid dynamic viscosity.
Results show a clear correlation between the carrying fluid dynamic viscosity and the number of clusters, where the fluid dynamic viscosity increase leads to more clusters. Also, as fluid dynamic viscosity increases, the size of particle clusters slightly increases. However, fluid dynamic viscosity does not have a strong effect on the shape of particle clusters. The majority of particle clusters are rounded and small. Higher fluid dynamic viscosity helps to move the distance of particle clusters closer.

\section{Conclusions}

The study uses plexiglas laboratory experiments to better understand particle agglomeration and clustering mechanisms during proppant-water slurry flow through fracture intersection, including coupled effects of proppant volumetric concentration, slurry flow rates and carrying fluid dynamic viscosities on agglomeration. For experiment analysis and post-processing, high-resolution high-speed camera recorded a detailed particle flow pattern. GeoPIV-RG analysis helped to visualize particle flows and quantify velocities. By assigning a color scheme to velocity fields, potential particle clusters that have similar flow velocity within a small region were visible. Generally, it was concluded that fluid dynamic viscosity, fluid flow rate, and proppant volumetric concentration play a strong role in particle clustering processes, while the intersection angle has less effect. Also, coupled proppant volumetric concentration and fluid flow rate effects are more pronounced than other combinations of parameters.

Visual inspection is not optimal for capturing particle agglomerations with small proppant diameters. We were unable to observe potential particle clusters by visual inspection for most of the experiments; even for those experiments where we captured clusters by visual inspection, they were observable only within a certain area. GeoPIV-RG analysis of the measured velocity fields within the slurry greatly helped us to identify particle agglomerations and captures more details than visual observation. We were able to identify the size and shape, even the spacing, of particle clusters. 
Carrying fluid dynamic viscosity plays a significant role in cluster formations, frequency, and shape when other factors remain unchanged. An increase in the fluid dynamic viscosity leads to more clusters and increased cluster sizes (cluster diameter from $0.25-0.5 \mathrm{~cm}$ at lowest viscosity to $1-1.5 \mathrm{~cm}$ at highest viscosity). However, the fluid dynamic viscosity does not have a strong effect on the shape of particle clusters. Although most particle clusters are rounded and small, higher carrying fluid dynamic viscosity tends to close the distance between particle clusters (cluster maximum distance from $4 \mathrm{~cm}$ at lowest viscosity to $1.5 \mathrm{~cm}$ at highest viscosity).

This study reveals for the first time that certain parameters, like the proppant volumetric concentration and the fluid flow rate, are more closely coupled with each other when governing the occurrence of particle agglomerations than other parameters. On contrary, it was also found that the fluid dynamic viscosity and the fracture intersection angle do not clearly couple with other factors regarding the formation of particle agglomeration.

When analyzing the coupled effect of the flow rate and the proppant volumetric concentration, it shall be separated into four different scenarios: lower proppant volumetric concentration with different flow rates, higher proppant volumetric concentration with different flow rates, lower flow rate with different proppant volumetric concentrations, and higher flow rate with different proppant volumetric concentrations.

When considering slurry condition under a lower proppant volumetric concentration but varying flow rates, slower flow rate causes larger (cluster diameter about 1-2 cm) and elongated clusters toward the fracture bottom, while faster flow rate causes smaller (cluster diameter about $0.25-1.5 \mathrm{~cm}$ ) and suspended particle clusters. An increase in fluid velocity significantly decreases the size of particle clusters by breaking larger particle clusters into more approximate smaller clusters (cluster maximum distance from $2.5 \mathrm{~cm}$ to $0.75 \mathrm{~cm}$ ); thus, the general shape becomes more complex.

When considering slurry conditions under a higher proppant volumetric concentration but varying flow rates, particle clusters are smaller and more rounded and occur at a larger amount of numbers, for both flow rates, comparing with lower proppant volumetric concentration condition.

When considering slurry conditions under a lower flow rate but varying proppant volumetric concentrations, less proppant volumetric concentration will have longer and larger clusters at the bottom. As proppant volumetric concentration increases, the differences in sizes and shapes of particle clusters become clearer. An increase in proppant volumetric concentration will make the agglomeration more frequent, smaller (cluster diameter from $1-2.5 \mathrm{~cm}$ to $0.25-1 \mathrm{~cm}$ ), more rounded and more regularly shaped. Also, the agglomerates are more uniformly suspended across the observed fracture area.

When considering slurry conditions under a higher flow rate but varying proppant volumetric concentrations, particle clusters show a similar level of agglomeration across different proppant volumetric concentrations. An increase in proppant volumetric concentration plays a less significant role comparing with lower flow rate conditions. Particle clusters are generally irregular, uniformly distributed and vary from small to large sizes. Particle clusters are broken into smaller and rounded shapes mostly due to the effect of the flow rate itself.

The effect of fracture intersection angle is the least significant factor that affects particle clustering, and the coupling effects with other factors are insignificant. We barely see any differences in sizes, shapes and spacing of particle clusters between $30^{\circ}$ and $45^{\circ}$ intersection angles. The shapes are both rounded and elongated in both fracture intersection angles. The distance of particle clusters is moderately separated for both fractures. For the smaller fracture intersection angle, the groups of clusters are inclined to the right in the top region.

Maintaining a good proppant transport behavior is very critical in hydraulic fractures. Proppant agglomeration is one of the threats to a good transport performance. Since viscosity helps to transport proppant at further distance while it also causes more agglomeration which may causing clogging, we suggest caution when using carrying fluid with very high viscosity. Since fracture intersection angle does not has strong effect on particle agglomeration, we do not worry about how fracture geometry will cause potential clogging due to particle agglomeration. Since proppant volumetric concentration and fluid flow rate are coupled with each other, we suggest using lower proppant concentration at a higher fluid flow rate to minimize the occurrence of proppant agglomeration and limit the size of agglomeration.

Author's Contribution Wenpei Ma contributed to conceptualization, methodology, investigation, formal analysis, writing — original draft, writing — review and editing; Ingrid Tomac contributed to conceptualization, methodology, writing—review and editing, supervision, project administration, funding acquisition.

Funding This work was supported by the U.S. National Science Foundation, Division of Civil, Mechanical and Manufacturing Innovation [grant number NSF CMMI 1563614] and the Regents of the University of California, San Diego.

Data availability All authors make sure that all data and materials as well as software application or custom code support their published claims and comply with field standards.

Code availability upon request. 


\section{Declarations}

Conflict of interest The authors have no conflicts of interest to declare that are relevant to the content of this article.

Open Access This article is licensed under a Creative Commons Attribution 4.0 International License, which permits use, sharing, adaptation, distribution and reproduction in any medium or format, as long as you give appropriate credit to the original author(s) and the source, provide a link to the Creative Commons licence, and indicate if changes were made. The images or other third party material in this article are included in the article's Creative Commons licence, unless indicated otherwise in a credit line to the material. If material is not included in the article's Creative Commons licence and your intended use is not permitted by statutory regulation or exceeds the permitted use, you will need to obtain permission directly from the copyright holder. To view a copy of this licence, visit http://creativecommons.org/licenses/by/4.0/.

\section{References}

Aimene YE, Ouenes A (2015) Geomechanical modeling of hydraulic fractures interacting with natural fractures-Validation with microseismic and tracer data from the Marcellus and Eagle Ford. Interpretation. https://doi.org/10.1190/int-2014-0274.1

Alotaibi MA, Miskimins JL (2015) Slickwater Proppant Transport in Complex Fractures: New Experimental Findings \& Scalable Correlation. SPE Annual Technical Conference and Exhibition. https://doi.org/10.2118/174828-ms

Bec J, Celani A, Cencini M, Musacchio S (2005) Clustering and collisions of heavy particles in random smooth flows. Phys Fluids. 10(1063/1): 1940367

Chang O, Dilmore R, Wang JY (2017) Model development of proppant transport through hydraulic fracture network and parametric study. J Petrol Sci Eng 150:224-237. https://doi.org/10. 1016/j.petrol.2016.12.003

Dayan A, Stracener SM, Clark PE (2009) Proppant Transport in Slickwater Fracturing of Shale Gas Formations. SPE Annual Technical Conference and Exhibition. https://doi.org/10.2118/ 125068-ms

Eskin D, Miller MJ (2008) A model of non-Newtonian slurry flow in a fracture. Powder Technol 182:313-322

Fernández ME, Sánchez M, Pugnaloni LA (2019) Proppant transport in a scaled vertical planar fracture: Vorticity and dune placement. J Petrol Sci Eng. 173:1382-1389. https://doi.org/10.1016/j.petrol. 2018.10.007

Fiabane L, Zimmermann R, Volk R, Pinton JF, Bourgoin M (2012) Clustering of finite-size particles in turbulence. Phys Rev E. https://doi.org/10.1103/PhysRevE.86.035301

Fjaestad D, Tomac I (2019) Experimental investigation of sand proppant particles flow and transport regimes through narrow slots. Powder Technol 343:495-511. https://doi.org/10.1016/j.powtec. 2018.11.004

Frash LP, Hampton J, Gutierrez M et al (2019) Patterns in complex hydraulic fractures observed by true-triaxial experiments and implications for proppant placement and stimulated reservoir volumes. J Petrol Explor Prod Technol 9(4):2781-2792. https:// doi.org/10.1007/s13202-019-0681-2

Guala M, Liberzon A, Hoyer K, Tsinober A, Kinzelbach W (2008) Experimental study on clustering of large particles in homogeneous turbulent flow. J Turbul. https://doi.org/10.1080/1468524080 2441118
Gualtieri P, Picano F, Casciola CM (2009) Anisotropic clustering of inertial particles in homogeneous shear flow. J Fluid Mech 629:25-39. https://doi.org/10.1017/S002211200900648X

Gustavsson K, Vajedi S, Mehlig B (2014) Clustering of particles falling in a turbulent flow. PhysRev Lett. https://doi.org/10.1103/PhysR evLett.112.214501

Hampton J, Gutierrez M, Frash L (2019) Predictions of macro-scale fracture geometries from acoustic emission point cloud data in a hydraulic fracturing experiment. J Petrol Explor Prod Technol 9(2):1175-1184. https://doi.org/10.1007/s13202-018-0547-z

Ho CA, Sommerfeld M (2002) Modelling of micro-particle agglomeration in turbulent flows. Chem Eng Sci 57(15):3073-3084. https:// doi.org/10.1016/S0009-2509(02)00172-0

Huang J, Safari R, Perez O, Fragachan FE (2019) Reservoir DepletionInduced Proppant Embedment and Dynamic Fracture Closure. Soc Petrol Eng. https://doi.org/10.2118/195135-MS

Kesireddy VR (2017) Quantifying ceramic proppant transport in complex fracture networks [master thesis]. Missouri University of Science and Technology, Rolla, Missouri

Kou R, Moridis GJ, Blasingame T (2018) Field Scale Proppant Transport Simulation and Its Application to Optimize Stimulation Strategy. Proceedings of the 6th Unconventional Resources Technology Conference. https://doi.org/10.15530/urtec-2018-2878230

Kumar D, Ghassemi A. Modeling and Analysis of Proppant Transport and Deposition in Hydraulic/Natural Fracture Networks. Proceedings of the 7th Unconventional Resources Technology Conference. 2019. doi:https://doi.org/10.15530/urtec-2019-243

Li S, Marshall JS, Liu G, Yao Q (2011) Adhesive particulate flow: The discrete-element method and its application in energy and environmental engineering. Prog Energy Combust Sci 37(6):633-668. https://doi.org/10.1016/j.pecs.2011.02.001

Li N, Li J, Zhao L, Luo Z, Liu P, Guo Y (2016) Laboratory Testing and Numeric Simulation on Laws of Proppant Transport in Complex Fracture Systems. SPE Asia Pacific Hydraul Fract Conf. https:// doi.org/10.2118/181822-ms

Luo L, Tomac I (2018a) Experimental investigation of particle agglomeration effects on slurry settling in viscous fluid. Transp Porous Media 121(2):333-352. https://doi.org/10.1007/ s11242-017-0956-3

Luo L, Tomac I (2018b) Particle Image Velocimetry (PIV) Analysis of Particle Settling in Narrow Fracture Experiments. Geotech Test J 41(2):20170136. https://doi.org/10.1520/gtj20170136

Ma W, Perng J, Tomac I (2020) Experimental Investigation of Proppant Flow and Transport Dynamics Through Fracture Intersections. Geomech Energy Environ. https://doi.org/10.1016/j.gete. 2020.100232

Nandlal K, Weijermars R (2019) Drained rock volume around hydraulic fractures in porous media: planar fractures versus fractal networks. Petrol Sci 16(5):1064-1085. https://doi.org/10.1007/ s12182-019-0333-7

Pan L, Zhang Y, Cheng L et al (2018) Migration and distribution of complex fracture proppant in shale reservoir volume fracturing. Nat Gas Industry B 5(6):606-615. https://doi.org/10.1016/j.ngib. 2018.11.009

Raiskinmäki P, Aström JA, Kataja M, Latva-Kokko M, Koponen A, Jasberg A, Shakib-Manesh A, Timonen J (2003) Clustering and viscosity in a shear flow of a particulate suspension. Phys Rev E 68:061403. https://doi.org/10.1103/PhysRevE.68.061403

Reeks MW (2014) Transport, mixing and agglomeration of particles in turbulent flows. J Phys: Conf Ser. https://doi.org/10.1088/17426596/530/1/012003

Sahai R (2012) Laboratory Evaluation of Proppant Transport in Complex Fracture Systems, [MS Thesis], Golden. Colorado School of Mines, Colorado

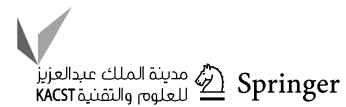


Sahai R, Moghanloo RG (2019) Proppant transport in complex fracture networks - A review. J Petrol Sci Eng. https://doi.org/10.1016/j. petrol.2019.106199

Sahai R, Miskimins JL, Olson KE (2014) Laboratory Results of Proppant Transport in Complex Fracture Systems. SPE Hydraul Fract Technol Conf. https://doi.org/10.2118/168579-ms

Saw EW, Shaw RA, Ayyalasomayajula S, Chuang PY, Gylfason A (2008) Inertial clustering of particles in high-Reynolds-number turbulence. Phys Rev Lett. https://doi.org/10.1103/PhysRevLett. 100.214501

Stanier S, Blaber J, Take W, White D (2015) Improved image-based deformation measurement for geotechnical applications. Can Geotech J 53(5):727-739. https://doi.org/10.1139/cgj-2015-0253

Taylor, GI.1935.Statistical Theory of Turbulence. Proceedings of the Royal Society A. 151:421-444. https://doi.org/10.1098/rspa.1935. 0158

Tomac I, Gutierrez M (2014) Fluid lubrication effects on particle flow and transport in a channel. Int J Multiph Flow 65:143-156. https:// doi.org/10.1016/j.ijmultiphaseflow.2014.04.007

Tomac I, Gutierrez M (2015) Micromechanics of proppant agglomeration during settling in hydraulic fractures. J Petrol Explor Prod Technol 5:417-434. https://doi.org/10.1007/s13202-014-0151-9

Tong S, Mohanty KK (2016) Proppant transport study in fractures with intersections. Fuel 181:463-477. https://doi.org/10.1016/j. fuel.2016.04.144

Wen Q, Wang S, Duan X, Li Y, Wang F, Jin X (2016) Experimental investigation of proppant settling in complex hydraulic-natural fracture system in shale reservoirs. J Nat Gas Sci Eng 33:70-80. https://doi.org/10.1016/j.jngse.2016.05.010

White DJ, Take WA (2002) GeoPIV: Particle Image Velocimetry (PIV) Software for Use in Geotechnical Testing. Cambridge Univ Eng Dep Tech Rep 322(October):15

Wong S-W, Geilikman M, Xu G (2013) The Geomechanical Interaction of Multiple Hydraulic Fractures in Horizontal Wells. Eff Sustain Hydraul Fract. https://doi.org/10.5772/56385

Zhang X, Jeffrey RG, Thiercelin M (2007) Deflection and propagation of fluid-driven fractures at frictional bedding interfaces: A numerical investigation. J Struct Geol 29(3):396-410. https://doi. org/10.1016/j.jsg.2006.09.013

Zhou L, Shen Z, Wang J, Li H, Lu Y (2019) Numerical investigating the effect of nonuniform proppant distribution and unpropped fractures on well performance in a tight reservoir. J Petrol Sci Eng 177:634-649. https://doi.org/10.1016/j.petrol.2019.02.086

Zou Y, Zhang S, Ma X, Zhou T, Zeng B (2016) Numerical investigation of hydraulic fracture network propagation in naturally fractured shale formations. J Struct Geol 84:1-13. https://doi.org/10.1016/j. jsg.2016.01.004

Publisher's Note Springer Nature remains neutral with regard to jurisdictional claims in published maps and institutional affiliations. 